\title{
O TRABALHO DO PROFESSOR NA ESCOLHA DO LIVRO DIDÁTICO: REVELAÇÕES DE UM DOCUMENTO OFICIAL
}

\author{
Gustavo Henrique da Silva Lima * \\ Betânia Passos Medrado
}

\begin{abstract}
Resumo: O presente estudo procurou investigar as representações sobre o agir docente em um texto oficial, que apresenta algumas orientações legais, norteando o processo de escolha do livro didático pelo professor. Para tal, nos ancoramos nos pressupostos do Interacionismo Sociodiscursivo sobre a relação linguagem e trabalho (cf. BRONCKART, 2008; MACHADO, 2004, 2009; SAUJAT, 2004; AMIGUES, 2004). A análise dos dados foi feita com base na semântica do agir proposta por Bronckart e Machado (2004). Os resultados evidenciaram que, no geral, há um apagamento do agir docente no documento oficial analisado uma vez que, nesse documento, o professor quase sempre é apresentado como coadjuvante no processo de escolha do livro didático.
\end{abstract}

Palavras-chave: Trabalho do professor. Livro didático. Documento oficial.

\begin{abstract}
This work aimed at investigating how teacher's practice is presented by an official document regarding the process of textbook choosing by the teacher. This study is based on the discussion on language and work according to the theory of Sociodiscursive Interactionism (cf. BRONCKART, 2008; MACHADO, 2004, 2009; SAUJAT, 2004; AMIGUES, 2004). The analysis was based on the performing semantics proposed by Bronckart and Machado (2004). Results have shown that the teacher performance regarding textbook choosing is often omitted by work prescriptions.
\end{abstract}

Keywords: Teacher's work. Textbook. Official document.

\section{Introdução}

Em meados da segunda metade do século XX, as pesquisas realizadas no âmbito da Linguística Aplicada (LA) seguiam um viés aplicacionista, cujos métodos, bastante reducionistas, focavam na resolução de problemas que eram identificados nas práticas em que o uso da linguagem se fazia presente. Nessa perspectiva, a preocupação da LA, a priori, residia apenas em buscar soluções para as "deficiências" e "lacunas" do processo de ensino aprendizagem de línguas. Com o advento das pesquisas no campo das Ciências Humanas, em especial, no âmbito da Sociologia, Filosofia, Psicologia e Antropologia, a LA passou a incorporar novos elementos aos seus pressupostos e métodos de investigação e, por conseguinte, ampliar seus horizontes de estudo em relação ao objeto investigado. Tal movimento fez com que as pesquisas em LA se expandissem e, gradativamente, assumissem um viés interdisciplinar, transdisciplinar ou até mesmo indisciplinar (cf. CELANI, 1992; KLEIMAN, 1992; GOMES DE MATOS, 1996; MOITA LOPES, 2006), estabelecendo um intenso e ininterrupto diálogo com outras áreas do conhecimento, no intuito de melhor compreender e explicar os fenômenos observados.

É justamente nesse ínterim que surgem novas abordagens de investigação em LA, dentre elas, o Interacionismo Sociodiscursivo, doravante ISD, construto teórico-metodológico idealizado por Bronckart (1999), cujo projeto era atribuir à psicologia da linguagem uma dimensão social e discursiva. De acordo com esse programa de estudo, a linguagem é

\footnotetext{
* Aluno do Programa de Pós-Graduação em Letras da Universidade Federal de Pernambuco - UFPE, Recife, Pernambuco, Brasil; e Professor Assistente da Universidade Federal Rural de Pernambuco - UFRPE, Garanhuns, Pernambuco, Brasil. Endereço eletrônico: ghlima@ hotmail.com .

** Professora Adjunta do Departamento de Letras Estrangeiras Modernas e do Programa de Pós-Graduação em Linguística (Proling) da Universidade Federal da Paraíba - UFPB, João Pessoa, Paraíba, Brasil. Endereço eletrônico: betamedrado@gmail.com .
} 
concebida como um artefato simbólico capaz de encapsular representações sobre o agir humano (cf. BRONCKART, 1999, 2006, 2008).

Na sociedade contemporânea, o trabalho é visto como atividade central da existência humana. Em outros termos, "o trabalho é uma forma de agir, ou uma prática, que seria própria da espécie humana" "(BRONCKART, 2008, p. 93). Sendo assim, acreditamos que é em meio a situações de trabalho que o agir pode ser evidenciado de forma mais intensa. Sob esse prisma, compreender o agir educacional é, antes de tudo, conceber o ensino como trabalho (cf. MACHADO, 2004, 2009; MACHADO et al., 2011), ou seja, é apreender significados e representações sobre a natureza desse trabalho nos discursos, por meio da análise de textos produzidos no ou sobre o trabalho educacional (cf. NOUROUDINE, 2002). Sendo assim, o presente artigo aborda a relação entre linguagem e trabalho com o objetivo de verificar as representações sobre o trabalho do professor no que concerne à escolha do livro didático em textos prescritivos oficiais. Para tanto, analisaremos algumas orientações legais sobre o trabalho docente contidas na Resolução n ${ }^{\circ} 60$ de 20 de novembro de 2009 (RE n60/2009) que versa sobre o Programa Nacional do Livro Didático (PNLD), à luz dos pressupostos teórico-metodológicos do ISD por nós aqui explicitados. Nossa hipótese é a de que, devido à natureza prescritiva do referido documento, a dimensão do trabalho do professor, no âmbito do PNLD, é restrita.

Iniciaremos nosso percurso com algumas considerações sobre as prescrições no trabalho docente. Na sequência, contextualizaremos o Livro Didático (LD) no âmbito dos documentos oficiais ao longo da história para, finalmente, adentrarmos nas especificidades concernentes às representações do trabalho docente no documento supracitado, a partir de uma análise interpretativa dos marcadores enunciativos, nos moldes de uma Semântica do Agir como proposta por Bronckart e Machado (2004).

\section{As prescrições e o trabalho docente}

No âmbito das pesquisas em LA, ainda é bastante comum encontrarmos estudos, principalmente os voltados para a didática de ensino (de natureza francófona), que restringem o trabalho do professor ao espaço físico da sala de aula, em especial, no que concerne às suas interações com os alunos, à utilização de estratégias, à organização interna do espaço e aos procedimentos e recursos didáticos utilizados para atingir determinados objetivos (BARBOSA, 2011). Sob esse prisma, a ação do professor é considerada de natureza essencialmente prescritiva, pois remete a uma concepção simplista de que "trabalhar é utilizar meios para atingir um fim" (AMIGUES, 2004, p. 37). Em outros termos, trabalhar é cumprir/atingir objetivos de ensino e aprendizagem. Nessa perspectiva, o trabalho do professor pode assumir um viés aplicacionista, uma vez que a finalidade dos estudos dessa natureza é servir como uma espécie de "modelo de referência" para as práticas escolares, as quais passam a ser avaliadas e consideradas "boas" ou "ruins" a partir de parâmetros teóricometodológicos preestabelecidos por um observador externo "mais experiente". Ou seja, geralmente, a avaliação do trabalho docente é feita de forma vertical, pautada, muitas vezes, em critérios de "certo" ou "errado", sem que ao professor seja dada a oportunidade de refletir sobre sua própria ação, seu fazer pedagógico (cf. AMIGUES, 2004).

Por outro lado, ao afirmarmos isso, não estamos negando que as pesquisas em didática não reconheçam a atividade docente como trabalho. Como afirma Saujat (2004, p. 28), "não resta dúvida de que essas pesquisas consideram o ensino como um trabalho. Entretanto, o trabalho de ensino é aí reduzido, [...], a seu objeto, à sua significação objetiva: a

\footnotetext{
${ }^{1}$ Grifos do autor.
} 
transmissão de conhecimentos". Em outros termos, o que estamos tentando dizer é que a dimensão do trabalho do professor é muito mais complexa e vai além do espaço escolar. Nesse sentido, assumimos como objeto de estudo a atividade docente numa perspectiva ergonômica do trabalho que, por sua vez, pode ser entendida como "um conjunto de conhecimentos sobre o ser humano no trabalho e uma prática de ação que relaciona intimamente a compreensão do trabalho e sua transformação" (SOUZA-E-SILVA, 2004, p. 84). Tal posição implica em estabelecer, a priori, uma distinção entre tarefa e atividade. De acordo com Amigues (2004),

a tarefa refere-se ao que deve ser feito e pode ser objetivamente descrita em termos de condições e de objetivo, de meios (materiais, técnicos...) utilizados pelo sujeito. A atividade corresponde ao que o sujeito faz mentalmente para realizar essa tarefa, não sendo portanto diretamente observável mas inferida a partir da ação concretamente realizada pelo sujeito (AMIGUES, 2004, p. 39).

Assim, a tarefa é o que está prescrito para ser realizado e que pode ser de origem institucional (currículo, resoluções, etc.) ou, ainda, planificado pelo docente (plano de aula, planejamento anual, etc.). A atividade, por outro lado, diz respeito à organização mental do professor para realizar uma determinada tarefa e, dessa forma, não pode ser percebida em ações materializadas na sala de aula, mas sim apreendidas a partir do que ele diz sobre a realização destas. Nas palavras de Amigues (2004), ao retomar Clot (1999), "a atividade não se limitaria ao que é realizado pelo sujeito, mas compreenderia também o que ele não chega a fazer, o que se abstém de fazer, o que queria ter feito, etc." (AMIGUES, 2004, p. 40).

Todavia, é importante esclarecer que a atividade a qual nos referimos não pressupõe um sujeito desvinculado de qualquer interferência de ordem social, histórica e cultural, mas um sujeito " $d a$ e $n a$ história" (cf. FREITAS, 1995). Nessa linha de raciocínio, a atividade docente é social e historicamente situada e, como tal, é orientada, de acordo com Amigues (2004) e Saujat (2004), por prescrições (PCN, LDB, etc), as quais, quando submetidas ao coletivo da escola - grupo de pessoas e a memória coletiva que cada professor carrega em si-, passam por um processo de ressignificação que leva o trabalho à uma reorganização no que concerne, por exemplo, à realização de uma determinada tarefa ${ }^{2}$, à utilização de ferramentas didáticas (quadro negro, livro didático, textos, etc.) e à criação de regras de ofício (formas padronizadas/ritualizadas de ação no âmbito do trabalho, tais como, por exemplo, o modo como todos os professores iniciam a aula). Sob esse prisma, diferentemente do que ocorre nas pesquisas desenvolvidas no âmbito da didática de ensino, nas quais as prescrições determinam as ações docentes, o trabalho é visto aqui como "uma resposta às prescrições" (SOUZA-ESILVA, 2004, p. 91). Em outros termos, na perspectiva por nós aqui assumida, os textos prescritivos são constitutivos da atividade docente, uma vez que, segundo Amigues (2004),

o trabalho do professor inscreve-se em uma organização com prescrições vagas, que levam os professores a redefinir para si mesmos as tarefas que lhes são prescritas, de modo a definir as tarefas que eles vão, por sua vez, prescrever aos alunos (AMIGUES, 2004, p. 42).

Em outros termos, na abordagem ergonômica do trabalho, as ações docentes estão sempre situadas entre o que lhes é prescrito por instâncias superiores e aquilo que os professores concebem como necessidades reais de aprendizagem dos seus alunos. Sendo

\footnotetext{
${ }^{2} \mathrm{Na}$ ergonomia, "realizar uma tarefa não consiste em apenas em atingir os objetivos propostos, mas implica também a realização de um projeto, de uma intenção a partilhar com os alunos; portanto, o meio, o grupo e o desenvolvimento da atividade são indissociáveis. (SOUZA-E-SILVA, 2004, p.93).
} 
assim, "a ação do professor consiste não apenas em operacionalizar as prescrições, mas também em colocá-las à prova e delas reapropriar-se para sua experiência pessoal" (SOUZAE-SILVA, 2004, p. 95).

Após essas considerações sobre a relação entre prescrições e o trabalho docente, faremos uma breve contextualização do Livro Didático à luz de alguns documentos oficiais que regulamentaram os procedimentos de avaliação e de escolha de tal ferramenta como instrumento de trabalho da atividade docente.

\section{O livro didático sob a lente da legislação: uma breve retrospectiva}

A história do LD no Brasil não pode ser dissociada de questões ideológicas e políticas. De acordo com Freitag et al. (1989, p. 11), "poder-se-ia mesmo afirmar que o livro didático não tem história própria no Brasil. Sua história não passa de uma sequência de decretos, leis e medidas governamentais que se sucedem, a partir de 1930, [...]" .

Ao realizar uma breve retrospectiva sobre a trajetória desse objeto de ensino em nosso país, os autores supracitados desvelam os bastidores das leis e decretos que regulamentaram as políticas públicas educacionais em torno do LD no país desde a primeira metade do século XX. Tudo remonta ao ano de 1937, quando o Ministério da Educação (MEC) institui o Instituto Nacional do Livro (INL) como órgão regulamentador das políticas de LD no Brasil. Competia ao INL firmar parcerias para legitimar o livro didático em escala nacional, de forma a garantir sua produção e distribuição (cf. FREITAG et al, 1989). No ano seguinte, é criada, por meio do Decreto-Lei 1.006, uma Comissão Nacional do Livro Didático (CNLD) que assumiu para si a responsabilidade de gerenciar as políticas de avaliação e produção do LD no Brasil, porém, sem levar em consideração os aspectos pedagógicos. Um ano após a sua criação, o CNLD é ampliado e fortalecido pelo Decreto-Lei ${ }^{\circ} 1.177$ que legitima aos membros da Comissão o controle absoluto de todo o processo de produção e circulação do LD no país (cf. FREITAG et al., 1989).

Já na década de 1960, período da Ditadura Militar no Brasil, são firmados vários convênios entre os governos brasileiro e americano, resultando na criação da Comissão do Livro Técnico e do Livro Didático (COLTED). O objetivo era "tornar disponíveis cerca de 51 milhões de livros para os estudantes brasileiros no período de três anos". (FREITAG et al., 1989 , p. 14). Também estava previsto no acordo a instalação de bibliotecas e o treinamento de professores em todas as esferas governamentais (federal, estadual e municipal). A reação dos especialistas em educação na época foi imediata, pois compreendiam que o acordo centralizava as políticas de LD do Brasil nas mãos do governo americano, restringindo o papel do MEC e da COLTED a meras unidades executoras. Em 1968 é criada a Fundação Nacional de Material Escolar (FENAME), órgão que, anos mais tarde, passaria a assumir o Programa de Livro Didático, até então sob responsabilidade do INL.

Somente a partir dos 1980, com o lançamento do PLIDEF (Programa do Livro Didático-Ensino Fundamental), é que as políticas públicas de LD foram ampliadas, passando a atender a população de baixa renda. A aprovação da Lei 7.091 institui a Fundação de Assistência ao Estudante (FAE), órgão vinculado ao MEC, que passa a agregar todos os programas assistencialistas voltados a estudantes da educação básica das redes públicas de ensino em todo o país. Essa medida, entretanto, desagradou a especialistas que alertaram o governo sobre as implicações dessa centralização, tais como a falta de cumprimento de prazos na distribuição dos LD, a unilaterização do processo de escolha do LD no âmbito das secretarias estaduais de educação e outros órgãos afins, a ação de atravessadores, etc. (cf. Freitag et al., 1989). A resposta a tais denúncias culminou com o decreto 91.542 de 19 de agosto de 1985 , o qual 
procura corrigir algumas das anomalias apontadas e busca a descentralização administrativa do Programa Nacional do Livro Didático, sugerindo que a escolha do livro seja feita pelo professor que o utiliza em sala de aula. (FREITAG et al., 1989, p. 17).

Desde então, o PNLD passou por inúmeras reformulações para atender às novas demandas sociais que se constituíram historicamente. Dessa forma,

o desenvolvimento do Programa esteve, desde então, condicionado, dentre outros fatores, pelo modo por meio do qual respondeu a dois problemas centrais: a questão da qualidade dos livros que eram adquiridos e a das condições políticas e operacionais do conjunto de processos envolvidos na escolha, aquisição e distribuição desses livros (BATISTA, 2003, p. 27).

Assim, a criação do PNLD foi motivada, inicialmente, pela necessidade de oferta de material didático a todas as escolas públicas brasileiras, sem qualquer critério que levasse em consideração a qualidade do material distribuído. Na época, vários estudos foram realizados, tomando o LD como objeto de investigação, e todos eles apontaram para lacunas que evidenciavam as fragilidades e inadequações teórico-metodológicas desse material. Em decorrência disso, em 1996, o MEC resolve instituir uma comissão de especialistas de diferentes áreas de conhecimento, com a tarefa de avaliar e estabelecer padrões de qualidade para o LD, a partir de alguns critérios comuns, tais como "a adequação didática e pedagógica, a qualidade editorial gráfica, a pertinência do manual do professor para uma correta utilização do livro didático e para a atualização do docente" (BATISTA, 2003, p. 30). Nesse mesmo ano, a publicação da Lei de Diretrizes e Bases da Educação Brasileira n ${ }^{\circ}$ 9.394/96 (LDB n ${ }^{\circ}$ 9.394/96) fortalece legalmente o PNLD, ao garantir, em seu artigo $4^{\circ}$, inciso VII, a realização de programas de apoio ao material pedagógico: "O dever do Estado com a educação escolar pública será efetivado mediante garantia de atendimento do educando no Ensino Fundamental, por meio de programas suplementares de material didático [...]" (BRASIL, 1996, p. 3).

Outros avanços na área educacional também são percebidos na LDB n 9.394/96, tais como a garantia da formação para o exercício da cidadania e o desenvolvimento de valores e atitudes (cf. BRASIL, 1996). No ano seguinte, são publicados os Parâmetros Curriculares Nacionais (PCN), cujo objetivo era oferecer subsídios teórico-metodológicos para o professor nas diferentes áreas de conhecimento. No referido documento, também é evidenciada a importância do LD na consolidação dos objetivos de ensino e aprendizagem para o ensino fundamental. De acordo com os PCN,

O livro didático é um material de forte influência na prática de ensino brasileira. É preciso que os professores estejam atentos à qualidade, à coerência e a eventuais restrições que apresentem em relação aos objetivos educacionais propostos (BRASIL, 1997, p. 96).

Esse novo paradigma educacional, que outrora se configurava, implicava em redirecionamentos não só nas práticas escolares, mas também na composição dos materiais didáticos. Seguiram-se, então, várias edições do PNLD e inúmeras modificações foram pensadas e incorporadas ao documento para melhor adequar o LD ao contexto educacional brasileiro. Recentemente, com base na LDB $n^{\circ} 9.394 / 96$, passou a entrar em vigor a $R E n^{\circ}$ 60/2009, a qual reorientou os critérios de avaliação e escolha dos LD para as escolas públicas de todo país. Essa mudança foi motivada, dentre outros fatores, pela recente aprovação no 
Congresso Nacional Brasileiro do Decreto Legislativo $\mathrm{n}^{\circ}$ 54, de 18 de abril de 1995, que dispõe sobre o Acordo Ortográfico da Língua Portuguesa, firmado em Lisboa, em 16 de dezembro de 1990, tal como consta no Decreto $\mathrm{n}^{\circ}$ 6.583, assinado em 29 de setembro de 2008, pelo até então Presidente da República, Luiz Inácio Lula da Silva. Segundo o referido documento, "a implementação do Acordo obedecerá ao período de transição de $1^{\circ}$ de janeiro de 2009 a 31 de dezembro de 2012, durante o qual coexistirão a norma ortográfica atualmente em vigor e a nova norma estabelecida" (BRASIL, 2008, Art. $2^{\circ}$, Parágrafo Único).

A seguir, apresentamos um quadro do plano global dessa Resolução, o qual nos possibilitará observar a organização de suas partes constitutivas. Vejamos:

Tabela 1: Plano global da RE nº6/2009

1. Citação do objeto da Resolução

2. Fundamentação Legal

3. Denominação completa da autoridade

4. Motivação da resolução

5. Disposições legais sobre o processo de escolha e distribuição dos Livros Didáticos.

5.1. Competências e atribuições das várias instituições e segmentos envolvidos

6. Disposições finais com identificação da autoridade que subscreve a Resolução

Feitas essas considerações, partiremos para a exposição dos parâmetros metodológicos utilizados na análise do agir docente no documento em foco.

\section{Parâmetros de análise}

No que concerne à análise do agir docente na RE $n^{\circ} 60 / 2009$, recorremos ao aparato metodológico da Semântica do Agir, proposto por Bronckart e Machado (2004), segundo o qual o agir docente pode ser interpretado à luz de algumas categorias de análise ${ }^{3}$. Para tal, fezse, necessário realizar uma análise dos aspectos linguístico-discursivos desses textos, conforme pressupostos do modelo elaborado por Bronckart (1999). De acordo com sua proposta, a análise textual engloba o contexto sociointeracional de produção, as características globais dos textos e a infraestrutura textual (cf. BRONCKART; MACHADO, 2004).

Nesse sentido, inicialmente foram coletadas informações referentes ao contexto socio-histórico de produção dos documentos em foco, "através da leitura de documentos existentes" (BRONCKART; MACHADO, 2004, p. 140). Após a conclusão dessa etapa, partimos para a identificação dos elementos constitutivos dos textos prescritivos, tais como "o tipo de suporte(s) em que o texto é veiculado, sua configuração global, com o exame da capa, do título, de suas divisões maiores, de seu tamanho, dos elementos paratextuais que o circundam, etc" (BRONCKART; MACHADO, 2004, p. 140), bem como o "a identificação inicial do gênero que o texto mobiliza, explícita ou implicitamente" (BRONCKART; MACHADO, 2004, p.144). Por fim, realizamos uma análise da infraestrutura do texto, observando o plano global, os tipos de discurso ${ }^{4}$ e as marcas enunciativas, as relações

\footnotetext{
3 Conforme Bronckart e Machado (2004), as categorias da semântica do agir ainda encontram-se em construção.

${ }^{4}$ De acordo com Bronckart (1999) os tipos de discurso são compreendidos como "formas linguísticas que são identificáveis nos textos e que traduzem a criação de mundos discursivos específicos, sendo esses tipos articulados entre si por mecanismos de textualização e por mecanismos enunciativos que conferem ao todo textual sua coerência sequencial e configuracional" (p. 149). Ainda no que concerne aos tipos de discurso, o autor supracitado propõe quatro grandes tipos. São eles: interativo e teórico (no eixo do expor); relato interativo e narração (no eixo do narrar). (cf. BRONCKART, 1999).
} 
predicativas, bem como os protagonistas e sua função sintático-semântica (no nosso caso, o professor).

No que concerne ao plano global, é importante ressaltar que a estrutura composicional do texto foi analisada sob uma perspectiva dialógica, ou seja, "como obedecendo a um objetivo específico, de acordo com as representações que o autor ${ }^{5}$ tem de seus destinatários" (BRONCKART; MACHADO, 2004, p. 145). Já em relação aos tipos de discurso, fizemos, inicialmente, um levantamento da incidência de unidades dêiticas, tais como "pronomes pessoais e possessivos de primeira e segunda pessoa do singular ou do plural, de advérbios de lugar e de tempo, (...) e das formas pessoais e temporais dos verbos." (BRONCKART; MACHADO, 2004, p. 147), a fim de verificar o valor que cada unidade adquire nos documentos oficiais supracitados. A realização de tal procedimento possibilitou identificar os tipos de discursos presentes no texto e suas implicações para um maior ou menor grau de desvelamento da subjetividade do autor, bem como do distanciamento deste em relação ao que diz. Fizemos, então, um levantamento e uma análise das relações predicativas ou das modalizações ${ }^{6}$ presentes nos textos e, por fim, identificamos, nos documentos supracitados, as unidades linguísticas que se referem ao professor, o que nos permitiu, a partir da análise dos tipos de frase ${ }^{7}$, identificar os papéis sintático-semânticos atribuídos a esse protagonista. De acordo com Bronckart e Machado (2004), inspirados na classificação proposta por Fillmore (1975), podemos distinguir os seguintes papéis:

- Agentivo, o ser animado responsável por um processo dinâmico, como é o caso de o professor no enunciado $O$ professor escreveu na lousa.

- Instrumental, o ser inanimado que é a causa imediata de um evento ou que contribui para a realização de um processo dinâmico, como um projeto de ensino, no enunciado "Com um projeto de ensino delineado, o professor pode desenvolvê-lo de várias maneiras."

- Atributivo (ou Experenciador), a entidade a quem é atribuído uma determinada sensação ou um determinado estado, como é o caso de $o$ professor, no enunciado "O professor tem os conhecimentos necessários para o exercício de sua profissão".

- Objetivo, a entidade que sofre um processo dinâmico, como é o caso de Essa versão dos PCNs, no enunciado "Essa versão dos PCNs deverá ser revista por professores de vários níveis de ensino."

- Beneficiário, o destinatário animado de um processo dinâmico, como $o$ professor, no enunciado "Os PCNs foram escritos para os professores".

- Factivo, que indica o estado ou o resultado final de uma ação, como os documentos, em, por exemplo, Os especialistas escreveram os documentos. (BRONCKART; MACHADO, 2004, p. 152)

Após realização da análise dos aspectos linguístico-discursivos do texto, foi feita uma reinterpretação dos resultados obtidos à luz de uma semântica do agir, tomando como pressupostos os conceitos de agir, atividade e ação, os quais "mobilizam ou explicitam as dimensões motivacionais (razões de agir, retrospectivas) e intencionais (finalidades do agir, prospectivas), assim como os recursos sincronicamente disponíveis para os agentes" (BRONCKART; MACHADO, 2004, p. 154). Outrossim, Bronckart e Machado (2004) propõem uma Semântica do Agir alicerçada a partir de três planos sobrepostos e

\footnotetext{
${ }^{5}$ Grifo dos autores.

${ }^{6}$ Para este procedimento, tomamos como base a distinção feita por Bronckart e Machado (2004) entre relações predicativas diretas e indiretas, bem como a classificação dos metaverbos feita pelos referidos autores em função de seus valores: deôntico, pragmático, psicológico, epistêmico e apreciativo.

${ }^{7}$ Assumiremos a distinção feita por Bronckart e Machado (2004) entre frases principais e subordinadas, frases com verbo na voz ativa (ou neutra) e como voz passiva; frases com verbo conjugado ou com infinitivo.
} 
complementares: a) o plano motivacional, no qual "distinguimos os determinantes externos ${ }^{8}$ do agir, que são de origem coletiva, de natureza material ou da ordem das representações sociais, e os motivos que são as razões de agir interiorizadas por uma pessoa particular". (BRONCKART; MACHADO, 2004, p. 155); b) o plano da intencionalidade, no qual "distinguimos as finalidades que são de origem coletiva e socialmente validadas, e as intenções, que são as finalidades do agir interiorizadas por uma pessoa particular" (BRONCKART; MACHADO, 2004, p. 155); c) o plano dos recursos para o agir, no qual fazemos a distinção entre os "instrumentos, que podem ser ferramentas concretas ou modelos para o agir, disponíveis no ambiente social, das capacidades, que são os recursos mentais ou comportamentais atribuídos a uma pessoa particular" (BRONCKART; MACHADO, 2004, p. 155). Por fim, para identificarmos os seres humanos envolvidos no agir (no nosso caso, o professor), utilizaremos o termo actantes. Se a esses actantes forem atribuídos capacidades, motivos e intenções próprias, então os denominaremos de atores. Todavia, se aos mesmos actantes não forem atribuídas essas propriedades, eles serão considerados meros agentes (cf. BRONCKART; MACHADO, 2004; MACHADO; CRISTÓVÃO, 2009).

\section{Análise da RE n60/2009}

Ao examinarmos as ocorrências do termo "professor" no documento, observamos que a referência ao termo é sempre feita no plural, com exceção de uma única ocorrência, em que o item lexical "professores" é retomado por um hiperônimo ("corpo docente"). Tal constatação evidencia, em alguns momentos, que os benefícios do PNLD são voltados a uma coletividade. Em outros termos, a RE n60/2009 concebe que as ações previstas na política de escolha e distribuição do LD fomentarão a ação dos professores no sentido de subsidiar a realização de atividades no âmbito de trabalho. Já em outros momentos, observamos que também são atribuídas responsabilidades a essa mesma coletividade no que se refere ao cumprimento das orientações/regulamentações durante o processo de escolha do LD. Ou seja, os docentes aparecem como sujeitos corresponsáveis pelo êxito das ações propostas pelo PNLD. Vejamos alguns exemplos:

\section{Exemplo 1:}

Art. $3^{\circ}$

II - o quantitativo a ser adquirido dos exemplares de livros didáticos para os alunos e professores e dos acervos de dicionários e obras complementares para as salas de aula será definido com base nas projeções de matrículas das escolas participantes para o ano letivo objeto do atendimento;

O exemplo acima trata dos critérios envolvidos na operacionalização do PNLD. Observamos que os professores são apresentados na função de Beneficiários da ação a ser realizada pelo produtor do texto $\left(\mathrm{MEC} / \mathrm{FNDE}^{9}\right)$, aparecendo em uma posição sintática inferior, ou seja, de complemento. Em tal posição, portanto, não lhes são conferidas intenções ou capacidades próprias para agir e, sendo assim, assumem a função de agentes, ou seja, meros coadjuvantes do processo. Esse apagamento do agir docente também foi identificado nos exemplos a seguir. O primeiro faz parte de um artigo da RE $n^{\circ} 60 / 2009$ que dispõe sobre a periodicidade de realização do PNLD, considerando os diferentes níveis de ensino da educação básica aos quais deve atender (Fundamental e Médio). Já o segundo trecho faz

\footnotetext{
${ }^{8}$ Grifo dos autores.

${ }^{9}$ Fundo Nacional de Desenvolvimento da Educação.
} 
parte de um dos incisos de um outro artigo que versa sobre divisão de responsabilidades para a execução do Programa. Senão, vejamos:

\section{Exemplo 2:}

Art. $4^{o}$

$\S 2^{\circ}$ - Os livros didáticos consumíveis serão entregues para utilização dos alunos e professores beneficiários, que passam a ter sua guarda definitiva, sem necessidade de devolução ao final de cada período letivo.

\section{Exemplo 3:}

Art. $7^{\circ}$, inciso III

c) monitorar a distribuição das obras até sua chegada efetiva na escola, garantindo acesso de alunos e professores aos materiais designados para uso coletivo ou individual.

<http://www.fnde.gov.br/arquivos/category/60-2012?download=3864:res060-20112009.>

Mais uma vez, verificamos que, em ambos os casos, os professores são situados na condição de Beneficiários da ação a ser realizada, ou seja, a distribuição dos LD. Sob esse prisma, não lhes são atribuídas propriedades do agir. Em outro trecho do documento, verificamos que "os professores" são apresentados como meros coadjuvantes que auxiliam no processo de escolha do LD, ou seja, como indivíduos que contribuem para a realização do processo. É o que ocorre, por exemplo, no trecho a seguir:

\section{Exemplo 4:}

Art. $7^{\circ}$

A execução do Programa ficará a cargo do FNDE e contará com a participação da SEB, das secretarias de educação dos estados, dos municípios e do Distrito Federal, das escolas participantes e dos professores, por meio de procedimentos específicos e em regime de mútua cooperação, de acordo com as competências seguintes:

<http://www.fnde.gov.br/arquivos/category/60-2012?download=3864:res060-20112009.>

Apenas no artigo sétimo da RE $n^{\circ}$ 60/2009 encontramos marcas textuais que evidenciam o agir docente no processo de escolha do LD:

\section{Exemplo 5:}

Art. $7^{\circ}$, inciso $V$

$\mathrm{V}$ - aos professores compete:

a) participar da escolha dos títulos para a respectiva escola, dentre aqueles selecionados no guia de livros didáticos distribuído pelo FNDE; e

b) observar, no que se refere ao processo de escolha, a proposta pedagógica e a realidade específica da sua escola.

<http://www.fnde.gov.br/arquivos/category/60-2012?download=3864:res060-20112009>

No exemplo 5, verificamos que os professores aparecem na condição de sujeitos da ação a ser realizada. Na referida posição, são atribuídos aos docentes motivos, intenções e capacidades que lhes permitem realizar a ação prescrita, atuando, portanto, como atores do processo.

Abaixo, apresentamos, de forma suscinta, uma análise das ocorrências do termo "professores" a partir dos pressupostos por nós aqui assumidos.

Tabela 2: Estatuto sintático-semântico do protagonista “professor” na RE n60/2009 


\begin{tabular}{|c|c|c|c|c|}
\hline Protagonista & $\begin{array}{l}\text { Função } \\
\text { sintática }\end{array}$ & $\begin{array}{c}\text { Função } \\
\text { semântica }\end{array}$ & $\begin{array}{l}\text { Tipo de } \\
\text { Frase }\end{array}$ & Verbo \\
\hline \multirow{10}{*}{ Professores } & Complemento & Beneficiário & $\begin{array}{c}\text { Subordinada } \\
\text { Passiva }\end{array}$ & ser adquirido \\
\hline & Complemento & Beneficiário & $\begin{array}{c}\text { Subordinada } \\
\text { Passiva }\end{array}$ & $\begin{array}{l}\text { serão } \\
\text { entregues }\end{array}$ \\
\hline & Complemento & Instrumental & $\begin{array}{c}\text { Subordinada } \\
\text { Ativa }\end{array}$ & $\begin{array}{l}\text { contará com a } \\
\text { participação } \\
\text { de }\end{array}$ \\
\hline & Complemento & Beneficiário & $\begin{array}{c}\text { Subordinada } \\
\text { Ativa }\end{array}$ & $\begin{array}{l}\text { objetivando a } \\
\text { participação } \\
\text { dos }\end{array}$ \\
\hline & Complemento & Instrumental & $\begin{array}{c}\text { Subordinada } \\
\text { Ativa }\end{array}$ & $\begin{array}{l}\text { garantindo a } \\
\text { participação } \\
\text { dos }\end{array}$ \\
\hline & Complemento & Beneficiário & $\begin{array}{c}\text { Subordinada } \\
\text { Passiva }\end{array}$ & $\begin{array}{l}\text { garantindo } \\
\text { acesso de }\end{array}$ \\
\hline & Sujeito & Agentivo & $\begin{array}{c}\text { Principal } \\
\text { Ativa }\end{array}$ & Participar da \\
\hline & Sujeito & Agentivo & $\begin{array}{c}\text { Principal } \\
\text { Ativa }\end{array}$ & Observar a \\
\hline & complemento & Beneficiário & $\begin{array}{c}\text { Subordinada } \\
\text { Passiva }\end{array}$ & $\begin{array}{l}\text { Serão } \\
\text { repassados } \\
\text { aos }\end{array}$ \\
\hline & complemento & Beneficiário & $\begin{array}{c}\text { Subordinada } \\
\text { Passiva }\end{array}$ & Instruir \\
\hline $\begin{array}{l}\text { Corpo } \\
\text { docente }\end{array}$ & complemento & Instrumental & $\begin{array}{c}\text { Subordinada } \\
\text { Ativa }\end{array}$ & $\begin{array}{l}\text { viabilizar } \\
\text { com a efetiva } \\
\text { participação } \\
\text { de }\end{array}$ \\
\hline
\end{tabular}

Observamos, no quadro acima, 10 (dez) ocorrências do item lexical "professores" no documento analisado e 01 (uma) ocorrência de retomada, por hiperônimo ("corpo docente"), desse termo. Em apenas duas delas (o equivalente a $18 \%$ do total de ocorrências) os professores são apresentados como Agentes em posição de sujeito. Ou seja, como indivíduos dotados de intenções e capacidades que lhes permite agir. Entretanto, na maioria das vezes (55\%), tais propriedades não lhes são conferidas e o professor assume, portanto, a função de Beneficiário, em posição de complemento, da ação a ser realizada pelo produtor. Em outros momentos (27\%), o termo "professores" aparece apenas na função de Instrumental, ou seja, como uma espécie de suporte ou meio para se realizar alguma ação pretendida.

\section{Considerações finais}

A análise da RE n60/2009 evidenciou algumas expectativas do MEC em relação ao trabalho do professor no processo de escolha do LD. Primeiramente, ressaltamos que as ações previstas para o PNLD tomam como referência uma coletividade, representada não só por professores da Educação Básica, mas também instituições e órgãos públicos, tais como o FNDE, as Secretarias Estaduais de Educação e as escolas públicas, todos figurando como actantes do Programa. No que concerne aos professores, observamos que, no geral, há uma restrição do trabalho docente, uma vez que os docentes aparecem quase sempre como agentes 
do processo, pois a eles não são conferidas capacidades e intenções próprias para intervir em outras instâncias do processo, a não ser no seu ambiente de trabalho: a escola. Assim sendo, há um quase apagamento do agir docente no texto oficial analisado. Por outro lado, o documento também evidencia o quanto é complexa a natureza do trabalho docente e revela que o agir docente vai muito além de simplesmente preparar e ministrar uma aula. Ou seja, as prescrições que perpassam a atividade docente mobilizam outras dimensões desse trabalho e desvelam uma pluralidade de ações que constituem o agir docente.

Esperamos, portanto, que as análises sobre as representações do trabalho do professor em textos oficiais que versam sobre a atividade educacional possam servir de ponto de partida não só para reflexões mais sistemáticas que permitam compreender a natureza e as dimensões do trabalho docente, mas, sobretudo, contribuam para que políticas públicas de educação possam, algum dia, conferir ao professor o merecido status de sujeito do seu próprio fazer e dizer.

\section{Referências}

AMIGUES, R. Trabalho do professor e trabalho de ensino. In: MACHADO, A. R. (Org.). $O$ ensino como trabalho. Londrina: Eduel, 2004. p. 35-54.

BARBOSA, G. A. S. A contribuição da sequência didática no desenvolvimento da leitura e da escrita no Ensino Médio: análise dos materiais didáticos "Sequência Didática artigo de opinião" e "pontos de vista". Presidente Prudente, SP, 2011. Dissertação (Mestrado). UNESP.

BARRICELLI, E. A reconfiguração pelos professores da proposta curricular de educação infantil. São Paulo, 2007. Dissertação (Mestrado em Linguística Aplicada e Estudos da Linguagem). LAEL/PUC.

BATISTA, A. A. G. A avaliação dos livros didáticos: para entender o Programa Nacional do Livro Didático (PNLD). In: Livro didático de língua portuguesa, letramento e cultura escrita. Campinas: Mercado de Letras, 2003.

BRASIL. MEC. Lei de Diretrizes e base da Educação Nacional - LDB. Centro de documentação do Congresso Nacional. Brasília, DF, 1996.

BRASIL. SEF. Parâmetros curriculares nacionais: introdução aos parâmetros curriculares nacionais. Brasília: MEC/SEF, 1997. 126p.

BRASIL. Decreto $n^{o}$ 6.583, de 29 de setembro de 2008. Disponível em: <http://www.planalto.gov.br/ccivil_03/_Ato2007-2010/2008/Decreto/D6583.htm>, 2008. Acesso em: 28 fev. 2011.

BRASIL. Resolução $n^{\circ} 60$ de 20 de novembro de 2009. Disponível em: <http://www.fnde.gov.br/arquivos/category/60-2012?download=3864:res060-20112009>

BRONCKART, J. P. O Agir nos discursos: das concepções teóricas às concepções dos trabalhadores. Campinas: Mercado de Letras, 2008.

BRONCKART, J. P. Atividade de linguagem, discurso e desenvolvimento humano. Campinas: Mercado de Letras, 2006. 
BRONCKART, J. P. Atividades de linguagem, textos e discursos: por um interacionismo sócio-discursivo. São Paulo: EDUC, 1999.

BRONCKART, J. P.; MACHADO, A. R. Procedimentos de análise de textos sobre o trabalho educacional. In: MACHADO, A. R. (org.). O ensino como trabalho. Londrina: Eduel, 2004. p. 131-166.

CLOT, Y. La fonction psychologique du travail. Paris: P.U.F., 1999.

FREITAG, B. et al. O livro didático em questão. São Paulo: Cortez, 1989.

FREITAS, M. T. de A. Textos de Bakhtin e Vygotsky: um encontro possível. Texto apresentado no Colóquio Internacional Dialogismo: 100 anos de Bakhtin. São Paulo: USP, 1995.

GOMES DE MATOS, F. Pedagogia da Positividade, comunicação construtiva em Português. Recife, UFPE, 1996.

KLEIMAN, A. B. O ensino de línguas no Brasil. In: PASCHOAL, M. S. Z. de; CELANI, M. A. A. (Org.). Lingüística aplicada. Da aplicação da lingüística à transdisciplinaridade. São Paulo, Educ, 1992.

MACHADO, A. R. et al. Linguagem e Educação: o trabalho do professor em uma nova perspectiva. Campinas: Mercado de Letras, 2009.

MACHADO, A. R.; CRISTÓVÃO, V. L. L. Representações sobre o professor e o seu trabalho em proposta institucional brasileira para a formação docente. In: MACHADO, A. R. et al. Linguagem e Educação: o trabalho do professor em uma nova perspectiva. Campinas: Mercado de Letras, 2009.

MAZZILLO, T. M. da F. O trabalho do professor de língua estrangeira representado e avaliado em diários de aprendizagem. São Paulo, 2006. Tese (Doutorado em Linguística Aplicada e Estudos da Linguagem). LAEL/PUC.

MOITA LOPES, L. P. Por uma linguística aplicada indisciplinar. $2^{\text {a }}$ ed. São Paulo: Parábola Editorial, 2006.

NOUROUDINE, A. A linguagem: dispositivo revelador da complexidade do trabalho. In: SOUZA-E-SILVA, M. C. P. de e FAÏTA, D. (Orgs.). Linguagem e Trabalho: construção de objetos de análise no Brasil e na França. São Paulo: Cortez, 2002.

PASCHOAL, M.S.Z. de; CELANI, M. A. A. (Orgs.). Lingüística aplicada: da aplicação da lingüística à transdisciplinaridade. São Paulo: Educ., 1992.

SAUJAT, F. O trabalho do professor nas pesquisas em educação: um panorama. In: MACHADO, A. R. (Org.). O ensino como trabalho. Londrina: Eduel, 2004. p. 3-34.

SOUZA-E-SILVA, M. C. P.de. O ensino como trabalho. In: MACHADO, A. R. (Org.). $O$ ensino como trabalho. Londrina: Eduel, 2004. p. 81-104. 
Recebido em: outubro de 2013.

Aprovado em: abril de 2014. 